\title{
Fault Permeability and Strength Evolution Related to Fracturing and Healing Episodic Processes (Years to Millennia): the Role of Pressure Solution
}

\author{
J.-P. Gratier \\ LGIT, Observatoire, Université Joseph Fourier - CNRS, Maison des Géosciences, rue de la Piscine, 38041 Grenoble - France
}

Résumé - Évolution de la perméabilité et de la résistance des failles associée à des processus épisodiques de fracturation et colmatage (années - millénaires) : le rôle de la dissolution cristallisation sous contrainte - Il est bien connu que les fluides circulent le long des failles, mais il est aussi démontré que les failles se comportent en barrières imperméables. Il faut donc considérer que les failles puissent être successivement des chemins ouverts et fermés. À l'échelle de temps des activités humaines (années à millénaires), l'étude du cycle sismique offre la possibilité de construire un modèle de telles évolutions. Selon ce modèle, la fracturation sismique (ou hydraulique) ouvre les chemins des fluides de manière quasi-instantanée le long des failles avec des processus d'amollissement et de fluage post-fracturation. La fermeture de ces chemins de fluide par cicatrisation de la faille est beaucoup plus progressive, associée à un durcissement et une reconstitution de pression des fluides. De tels comportements transitoires ont des conséquences majeures dans les études :

- de l'évolution de la perméabilité le long des failles, avec application à l'exploitation de réservoirs pétroliers et aux stockages de fluides et de déchets ;

- de l'évolution des flux de fluides le long des failles avec application au bilan des échanges et à l'évolution du climat à l'échelle de la terre;

- du temps de retour des séismes et de la probabilité de leur occurrence.

Le but est de comprendre et d'évaluer la cinétique des processus et donc les temps caractéristiques spécifiques des cycles de fracturation et de colmatage. Des résultats d'expériences de laboratoire et d'étude de failles naturelles sont présentés qui montrent comment des processus de dissolution cristallisation sous contrainte peuvent expliquer à la fois les processus de fluage et de colmatage, et la façon dont ils sont associés dans la nature. Les divers processus de cicatrisation des failles sont discutés, avec leurs temps caractéristiques très variés de quelques semaines à des millénaires. On montre comment ils peuvent être intégrés dans des lois de fluage et de colmatage. Les expériences de laboratoire en donnent les valeurs de certains paramètres (cinétiques, thermodynamiques). D'autres paramètres de ces lois doivent cependant toujours être évalués à partir d'études de structures naturelles (géométrie des chemins de transfert, conditions de pression et température, nature des fluides et des minéraux). Ainsi, la durée des cycles de fracturation et colmatage est reliée, d'une certaine façon, au contexte géologique de la zone de faille. Finalement, comme ces processus d'évolution de perméabilité, de pression fluide et de résistance mécanique interagissent et se produisent à différentes échelles de temps et d'espace, ils doivent être intégrés dans des modèles numériques qui sont brièvement discutés. 


\begin{abstract}
Fault Permeability and Strength Evolution Related to Fracturing and Healing Episodic Processes (Years to Millennia): the Role of Pressure Solution - It is well known that fluids flow through faults and fractures but it is also demonstrated that fault zones act as impermeable barriers. Consequently, one must consider that faults are successively open and closed paths for fluids. On the human-activity time scale (years to millennia), studies of the seismic cycle offer the possibility of making a model of such evolution. According to this model, seismic (or hydraulic) fracturing opens fluid paths almost instantaneously through the faults with associated weakening and post-fracturing creep processes. Fault healing processes then progressively close such fluid paths, associated with fault strengthening and fluid pressure recovery. Such transient behaviors have major consequences in the studies of:

- the evolution of permeability along faults with application to oil-field reservoir exploitation and fluid and waste storage;

- the evolution of fluid fluxes along faults with application to mass balance and climate evolution on the scale of the earth;

- the timing of earthquakes and the probability of their occurrence.

The aim is to understand and evaluate the kinetics of the processes and the specific characteristic times of the fracturing and healing cycles. Results from laboratory experiments and natural fault studies are presented that show how pressure solution processes can explain both creep and sealing processes and the way they are associated in nature. The various fault-healing processes are discussed with their various characteristics in times from weeks to millennia. It is shown how they can be integrated into creep and sealing laws. Laboratory experiments give the values of some parameters of the laws (kinetics, thermodynamic). Other parameters must always be evaluated from the study of natural structures (geometry of path transfer, pressure and temperature conditions, nature of minerals and fluids). Consequently, the duration of the fracturing and sealing cycle is related to some extent to the geological context of a faulted area. Finally, as the mechanisms of permeability and strength evolution interact and occur on various scales of time and space, they must be integrated into numerical models, which are briefly discussed.
\end{abstract}

\section{INTRODUCTION}

Faults are linked to a wide range of global phenomena including opening and closure of oceans, rise and fall of mountains ranges, and fluid transfers from solid earth to its fluid envelope (Handy et al., 2007). Socio-economic consequences are important, from earthquake hazard to long-term climate change, from mineral and petroleum resource development to waste disposal and geological fluid storage. Moreover, it is the evolution of fault permeability and strength with time, which is a key parameter in most of these processes. We know that fluids flow through active faults. For example, Kennedy et al. (1997), and Pili et al. (1998) showed, from ${ }^{3} \mathrm{He} /{ }^{4} \mathrm{He}$ ratio studies, that fluids flow from depth with a mantle signature along the San Andreas fault. Meteoric waters are also able to percolate down into active faults (Labaume et al., 2004; Pizzino et al., 2004; Benedicto et al., 2008). Such fluid transfers along faults have been related to earthquake occurrence (Sibson et al., 1988) and the development of aftershocks (Miller et al., 2004). However, it is also well demonstrated that fault zones act as impermeable barriers (Person et al., 2007). Consequently, one must consider that faults are successively open and closed paths for fluids, the opening being linked to the earthquake occurrence or to any other fracturing and associated chemical mechanisms, and the closing being associated with post-fracturing healing. Evidence of increase in fault permeability associated with earthquake has been shown by Kitagawa et al. (2002), followed by after-slip healing and creeping processes (Freed, 2007; Li et al., 2003, 2007; Brenguier et al., 2008). The question is thus to identify the mechanism that can accommodate such fault permeability and strength evolution, and we will see that stress-driven mass transfer processes play a key role in such evolution; specifically, pressure solution processes. Actually, three ranges of characteristic times must be distinguished in fluid-rock interactions within active faults:

- seconds to minutes are characteristic of cataclastic failure. The role of fluids during such short intervals is mostly mechanical (fluid pressure) or catalytic (melting);

- days to thousands of years represent characteristic times for the evolution of the rheological and transport properties of rocks in human times;

- thousands to millions of years are characteristic times of chemical and mechanical differentiation processes associated with mass transfer that progressively localized deformation and transfer. 
In this paper we will mostly discuss the processes that occur on the human-activity time scale (years to millennia), even if processes that develop on a given time scale interact with processes that develop on other time scales. On the human-activity time scale most data are available from earthquake studies. This is why most of the examples given in this paper are related to this topic. However, the same processes occur in other contexts and understanding the mechanisms of fault permeability and strength evolution on this time scale remains a major fundamental task and has important consequences in terms of:

- the evolution of permeability along faults with application to oil-field reservoirs and fluid and waste storage;

- the evolution of fluid fluxes along faults with application to mass balance and climate evolution on the scale of the earth;

- the timing of earthquakes and the probability of their occurrence.

Earthquakes, especially the larger ones, occur at time intervals that are characteristic of the geodynamic context. Sykes and Menke (2006) gathered data on 15 seismic fault segments, lying at different plate boundaries, showing various repeat times ranging from 20 to 1000 years (with a mean value of 7 successive events of magnitude 6 to 8). Earthquake recurrence is explained by the strain buildup and release hypothesis (Reid, 1910). The idea is that large events do not rupture the same fault segment again until sufficient time has elapsed to re-establish the stresses that were partially discharged by the preceding event. This leads to the concept of seismic cycles, which requires that active faults strengthen (heal) between earthquakes (Marone, 1998). Post-seismic creep and associated porosity evolution (damage then recovery) observed on natural faults (Freed, 2007; Li et al., 2003, 2007; Brenguier et al., 2008) attest to this post-seismic healing process (Fig. la). Observations of seismic fault zones naturally exhumed from depth, or cored by drill holes, show that healing mechanisms of both the fault gouge and the damaged zone that lies around it (Gratier et al., 2003; Andreani et al., 2005) are related to stress-driven mass transfer processes that can explain both post-seismic mechanisms of creep and sealing. So, kinetics of healing by mass transfer processes play a key role in determining the repeat time of earthquakes, even if the seismic cycle timing is rather complex since it depends on several parameters:

- the rate of stress loading imposed by boundary conditions (plate tectonics);

- the rate of strength recovery;

- the rate of fluid pressure increase;

- the role of heterogeneities on all scales;

- the possibility of earthquake triggering by external forcing.

Each parameter has at least one specific characteristic time and the interactions between all these different times are complex but specific to a given region. For the same characteristic time and the same geological context, the mechanisms and the kinetics of permeability and strength evolution are the same for earthquake cycles and for fracturing and healing cycles that can occur in oil-fields and gas reservoirs that are submitted to intermittent fracturing processes either natural (earthquake) or artificial (fracturing promoted to increase fluid extraction, or fracturing induced by fluid storage).

The main problem is to identify these mechanisms and evaluate their kinetics. One problem is that such stress-driven mass transfer processes are very slow, resulting in strain rates ranging from $10^{-11}$ to $10^{-15} \mathrm{~s}^{-1}$, Rutter (1976), Pfiffner and Ramsay (1982). The fastest strain rates with such processes $\left(10^{-10} \mathrm{~s}^{-1}\right.$, Gratier et al., 2009) are found within active creeping zones, such as along the San Andreas fault (Titus et al., 2006). Reproducing such low strain rates on natural minerals in the presence of a fluid in the laboratory is therefore a challenge (Paterson, 2001). Strain rates as low as $10^{-11} \mathrm{~s}^{-1}$ may be registered in the lab (Gratier, 1993; Dysthe et al., 2003; Berest et al., 2004; Le Guen et al., 2007; Gratier et al., 2009), however the strain values are very low and not necessary representative of large finite deformation. Gaining one or two orders of magnitude on pressure solution strain rates may be achieved by using analogue material or by activating some parameters of the creep and sealing laws (Eq. 2-5): see discussion in Gratier and Gueydan (2007). Moreover, some parameters of the creep and sealing laws must always be evaluated, in parallel, from natural observations: geometry of path transfer, pressure-temperature conditions, and the nature of minerals and fluids. As a consequence, results are presented here which also came from observations and measurements on natural samples that have been recovered from drill holes through active faults (California, Taiwan, Japan and Greece).

Finally, as the post-fracturing mechanisms of healing and strengthening interact and develop on various characteristic scales of time and space (times of days to thousands of years, sizes of microns to kilometers), the various deformation laws have to be integrated into numerical models of the "fracturing and healing" cycles. Various methods need to be combined: rate-and-state friction laws, weakening-strengthening viscous models and fluid percolation, plus possible triggering effects not developed here. The paper presents only a few examples of such numerical methods.

We will consider rocks that are under stress in the presence of fluid that can react with at least part of the mineral of the rock, so we will mainly consider the role of pressure solution mass transfer. We will not discuss here other mechanisms of fault sealing (Knipe, 1992) that are not time dependent. For example, clay-rich sediment (more than $40 \%$ ) deform to produce clay smearing of fault that can significantly reduce their permeability (Bouvier et al., 1989; Yielding et al., 1997; Fisher and Knipe, 2001; Bretan et al., 2003). Clay smearing mostly occurs between the hanging wall and the footwall of clay-rich horizon but it could also result in injection through 

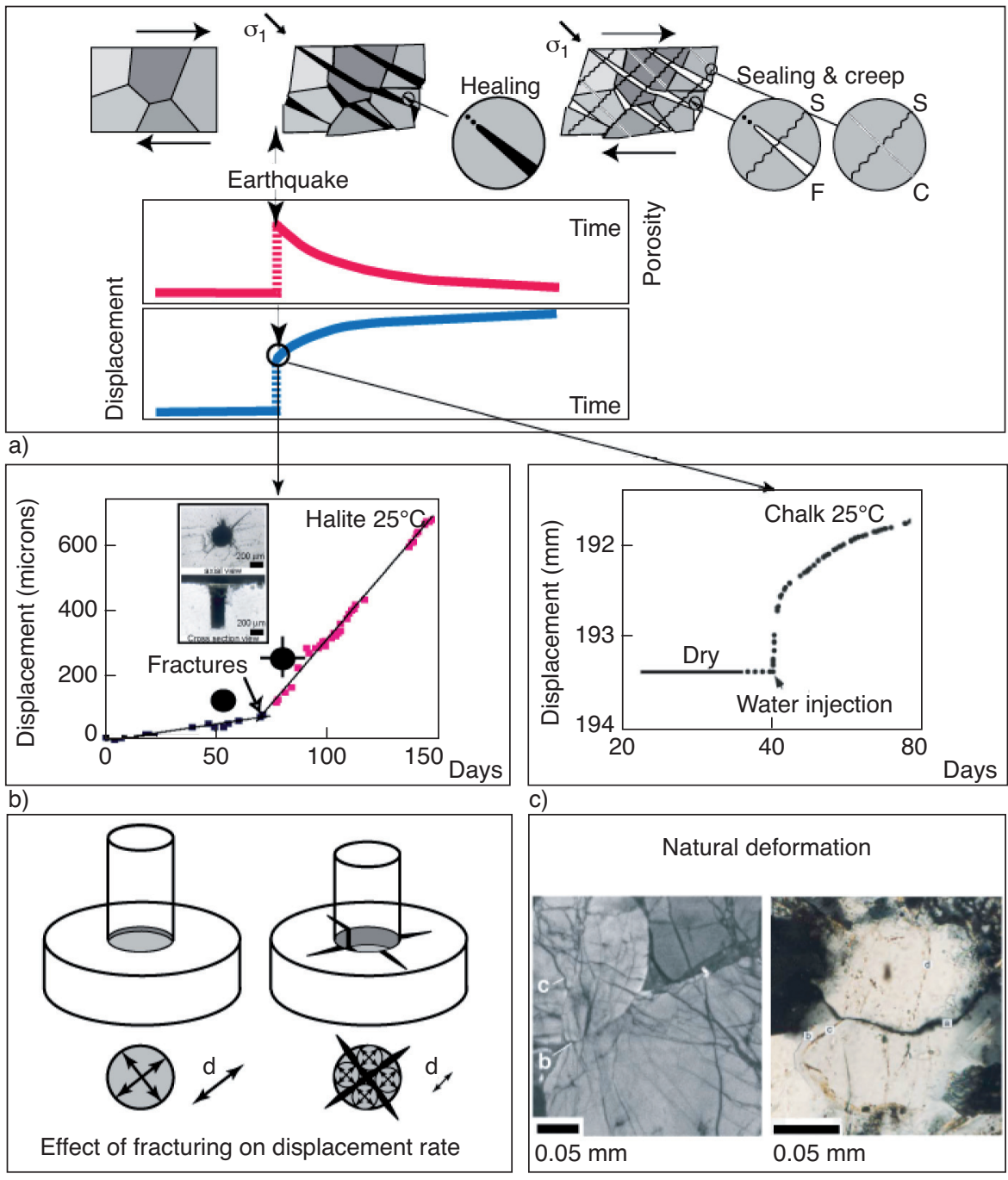

d)

e)

Figure 1

a) Schematic view of damaged zone deformation near active fault: earthquake-induced fracturing networks (black) that are progressively sealed by self-healing and sealing (white) associated with pressure solution creep processes (Fig. 3); (below) evolution of displacement and porosity with time during fracturing and healing cycles. b) Mechanism of fracture-induced deformation weakening: during indentation of halite by dissolution under stress, a dramatic change in displacement rate occurs when radial fractures develop (day 71). The effect of fractures is to reduce the mean distance of diffusion $d$ (Fig. Id, Eq. 4, 5 in the text), which is here the limiting process. c) Effect of water injection on deformation displacement during flow through experiment of chalk axial deformation. d) Effect of radial fracturing that drastically reduces the mean distance of mass transfer along fluid phase trapped under the indenter (parameter $d$ in $E q .4,5$ in the text). e) Fracturing associated with pressure solution at grain contacts in natural examples. Adapted from Gratier and Gueydan, 2007 (a, b), Brenguier et al., 2007 (a - bottom), Hellmann et al., 2002 (c), Gratier et al., 2009 (d), Labaume and Moretti, 2002 (e).

the less clay-rich sediment. Clay smearing can also changes the rheological properties of faults as clay minerals are likely to creep relatively easily (Prioul et al., 2000; Bourouis and Cornet, 2009).

The hydraulic structure of active faults is another important parameter that is not very well known. Recent works on the cored Nojima and Chelungpu active faults show relatively weak fine-grained gouges surrounded by more resistant damage zones of fractured rocks (Lockner et al., 2009). The damage zones act as high permeability conduits for both vertical and horizontal flow whereas the fine-grained gouge acts as relatively impermeable barriers than prevent significant fluid flow across the fault (Doan et al., 2007; Moore et al., 2009). 
In this context, we will discuss the evolution with time of the permeability and strength of the whole fault: the gouge and the damaged zone that lies around it, that can extend meters to kilometers away from the main gouge, trying to answer two major questions:

- how does fault strength evolve with time during the "fracturing and healing" cycle?;

- how do permeability and pore pressure evolve during the "fracturing and healing" cycle?

\section{HOW DOES FAULT STRENGTH EVOLVE WITH TIME DURING THE "FRACTURING AND HEALING" CYCLE?}

\subsection{Weakening Processes during the Fracturing Event}

A weakening process is defined here as a process that is associated with a decrease in the strength of the rock. Here, the strength is defined as the stress needed to accommodate creep at a given strain rate. The weakening process associated with a fracturing event has been observed in the lab by pressure solution creep experiments with the indenter technique (Gratier et al., 1999). With this experimental technique (Fig. 1d), the driving force of dissolution is promoted by a dead weight that presses onto an indenter that loads itself on a crystal surface, along which stress-enhanced dissolution occurs. Stress under the indenter increases the chemical potential of the solid compared with the solid free surface at zero stress far away from the indenter (Gibbs, 1877).

$$
\Delta \mu=\Delta f+V_{s} \Delta \sigma_{n}+\Delta E_{s}
$$

where $\Delta \mu$ is the difference in chemical potential of the dissolved component between the maximum stressed part (under the indenter) and the free solid/fluid surface away from the indenter, $\Delta \sigma_{n}$ is the difference between the normal stress component under the indenter and the fluid pressure $P_{f}$ on the solid away from the indenter, and is simply named $\sigma_{n}$ in the creep relations, $V_{s}$ is the molar volume of the solid. $E_{s}$ is the curvature-related potential. The molar Helmholtz free energy, $\Delta f$, gathers various contributions (Guéguen and Palciauskas, 1994; Leroy and Heidug, 1994) as the elastic strain energy and the plastic strain energy. Creep laws (Eq. 2-5) may be derived from the displacement rate $\Delta x / \Delta t$ versus stress $\sigma_{n}$ relationships when the characteristic length of the closed system is assumed to be equal to the indenter diameter (d), Gratier et al. (2009). Pressure solution being an in-series process: dissolution then diffusion then precipitation, two types of creep laws are expected depending on the limiting step of this in-series process (Gratier et al., 2009):

$$
\text { Model R: } \Delta x / \Delta t=\alpha k V_{s}^{2} \sigma_{n}^{n} / R T
$$

$$
\text { or: } \Delta x / \Delta t=\alpha^{\prime} k V_{s}\left(e^{\sigma_{n} V_{s} / R T}-1\right)
$$

is relevant if either dissolution or precipitation kinetics is the rate-limiting process: Raj (1982) or Spiers et al. (2004), respectively.

$$
\begin{aligned}
& \text { Model D: } \Delta x / \Delta t=\beta D w c V_{s}^{2} \sigma_{n}^{n} / R T d^{2} \\
& \text { or: } \Delta x / \Delta t=\beta, D w c V_{s}\left(e^{3 \sigma_{n} V_{s} / R T}-1\right) / d^{2}
\end{aligned}
$$

applies when diffusion flux through a fluid phase under stress below the indenter is the rate-limiting process: Rutter (1976) or Dewers and Ortoleva (1990), respectively.

In Equations (2) to (5), $\alpha, \alpha^{\prime}, \beta, \beta^{\prime}$ are dimensionless constants that depend on the geometry of the interface, $d$ is the indenter diameter $(\mathrm{m}), t$ is time $(\mathrm{s}), k$ is the kinetics constant for dissolution or precipitation reaction $\left(\mathrm{mol} . \mathrm{m}^{-2} \cdot \mathrm{s}^{-1}\right)$, $c$ is the solubility of the diffusing solid $\left(\mathrm{mol} . \mathrm{m}^{-3}\right), V_{s}$ is the molar volume of the stressed solid $\left(\mathrm{m}^{3} \cdot \mathrm{mol}^{-1}\right), R$ is the gas constant $\left(8.32 \mathrm{~m}^{3} \cdot \mathrm{Pa} \cdot \mathrm{mol}^{-1} \cdot \mathrm{K}^{-1}\right), T$ is the temperature $(\mathrm{K}), D$ is the diffusion constant along the stressed interface $\left(\mathrm{m}^{2} \cdot \mathrm{s}^{-1}\right)$ and $w$ is the thickness of the fluid interface (m) along which diffusion occurs. The factor 3 in the exponential of Equation (5) (Dewers and Ortoleva, 1990) reflects the fact that for balance of forces during a constant approach of two planar surfaces, the normal stress at the center of the contact between the surfaces is higher than the average stress across the contact (Weyl, 1959; Rutter, 1976).

In the example of Figure 1b, the same dead weight was maintained throughout the experiment. The only change was to induce radial fractures under the indenter at day 71 . The displacement rate of the indenter was constant during the first 71 days then it showed a sudden increase at the time of this fracturing, and it stayed constant at this new rate for the following 77 days. We interpreted fracturing to have augmented the rate of diffusive mass transfer along the contact between the indenter and halite (Gratier et al., 1999). Without fracturing, the displacement rate $\Delta x / \Delta t$ is controlled by the rate of mass transfer out of the nanometer-thick fluid film interface trapped beneath the indenter, and is inversely proportional to the square of the radius, $d$, of the indenter $(E q .4,5)$. The development of radial fractures, which are longer than the diameter of the indenter and several microns wide, induce some shortcuts for fast mass transfer away from the indenter contact area. Along these new paths, diffusive mass transfer occurs within the free fluid that fills the open fractures and fluxes along such paths are several orders of magnitude higher than along the thin-trapped fluid under stress. Therefore, fracturing renders the displacement rate inversely proportional to the square of the mean size of the small domains bounded by the radial fractures (Fig. Id). This explains the sudden increase in the displacement rate, as pressure solution indentation is here diffusion-controlled. This effect has been seen on numerous examples of halite indenting (Gratier, 1993; Gratier et al., 1999). This effect of 
fracturing that boosts the dissolution under stress may also be recognized in natural deformation. For example, pitted pebbles (Fig. 1e) that have long been attributed to pressure solution (Sorby, 1865) are always broken by numerous fractures (McEwen, 1978) that can be seen in cathodoluminescence studies (Labaume and Moretti, 2001). Therefore, fracturing weakens the rocks almost instantaneously by accelerating pressure solution creep. However, this effect is strongly nonlinear as fractures are progressively sealed, as seen on samples removed from active faults (Gratier et al., 2003). We show below that this sealing of the fracture progressively strengthens the rocks. Another effect of the fracturing process is linked to the fact that fluids can react with the minerals: fluid can dissolve or help transform them, and consequently weaken the whole aggregate. This effect, not detailed here, is well known in natural deformation (Handy, 1989; Evans and Chester, 1995; Gueydan et al., 2003; Boullier et al., 2004). Another chemical effect is the self-organization process that leads to flow-channeling during reactive fluid flow in porous medium (Ortoleva, 1994; Bazin et al., 1996; Renard et al., 1998; Hellmann et al., 1998; Worthington and Ford, 2009).

The effect of such "free-face" chemical processes on the evolution of strength and transfer properties must be added to the fracturing effect on pressure solution. The effect of chemical dissolution can be almost instantaneous in the lab: see, for example, the evolution of the strain rate when injecting water into dry chalk under stress, Figure 1c (Hellmann et al., 2002). However, in natural deformation, chemical reaction effects do not usually occur at the same characteristic times as the fracturing effect on pressure solution. They develop much more slowly so they interact with potential strengthening processes in a complex way that is not discussed in this paper.

\subsection{Strengthening Processes after the Fracturing Event}

Strengthening is commonly assumed to be linked to:

- increase in packing density of the damaged fault rock (Renard et al., 2004);

- contact strengthening, or;

- contact area increase (Niemeijer et al., 2008).

Strengthening may be reproduced in the lab but not necessarily with the same mechanism as in natural deformation. What geologists see in the field, either in the exhumed upper crust or on samples removed from a drill hole through an active fault, is that this strengthening is most often accommodated by mass transfer processes. Another common geological observation is that such sealed fractures are harder than the initial non-fractured rocks. This appears by the so-called bamboo-like structures (Fig. 2, Gratier and Vialon, 1980) where in a boudinage process, the boudins become progressively thinner than the interboudin sealed fractures. This is
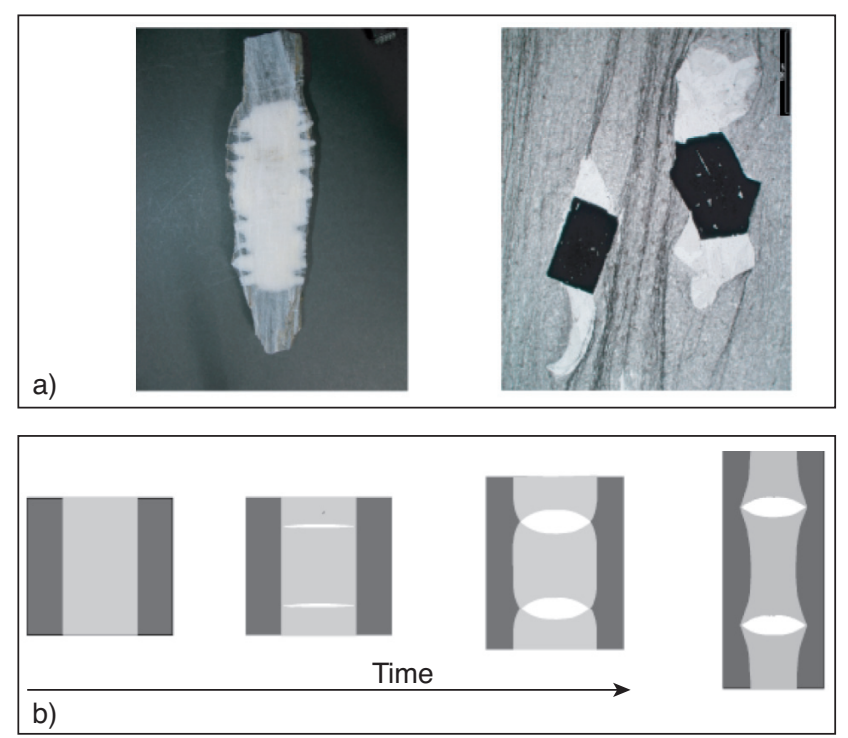

Figure 2

a) Example of extension veins in boudinaged structures (left) and crystallizations in pressure shadow (right) that are wider than the initial boudins and the rigid objects, respectively. b) Schematic evolution of extension veins in boudinaged structures: extension veins become wider than the boudins: this shows that sealed fractures are harder than the initial non-fractured rocks. The vein sealing is white (soluble species such as quartz and calcite), the initial rock is gray with a mixing of soluble and insoluble species (such as phyllosilicates), solution cleavage seams are black due to passive concentration of insoluble species.

because, when pressure solution is the deformation mechanism, it is easier to dissolve a polycrystalline rock that contains both soluble and insoluble species (the boudin) than to dissolve a monomineralic rock composed of only one soluble species (the interboudin sealed fractures). The reason is that the diffusion paths at the contact between soluble and insoluble minerals (such as phyllosilicates) are much faster than the diffusion paths at the contact between two soluble minerals. This is probably due to a more efficient healing of the grain boundary of the same species. This effect is also well demonstrated by experiments (Hickman and Evans, 1991; Zubsov et al., 2004). So, in natural processes, sealing of fractures strengthens the rocks, which become harder than before the fracturing process (at least when pressure solution is the main mechanism of deformation).

Several processes compete to seal the fractures in active faults. Actually, the characteristic times of post-fracturing healing vary from days to millennia (Fig. 3), depending on the processes involved (Eq. 2-5): 


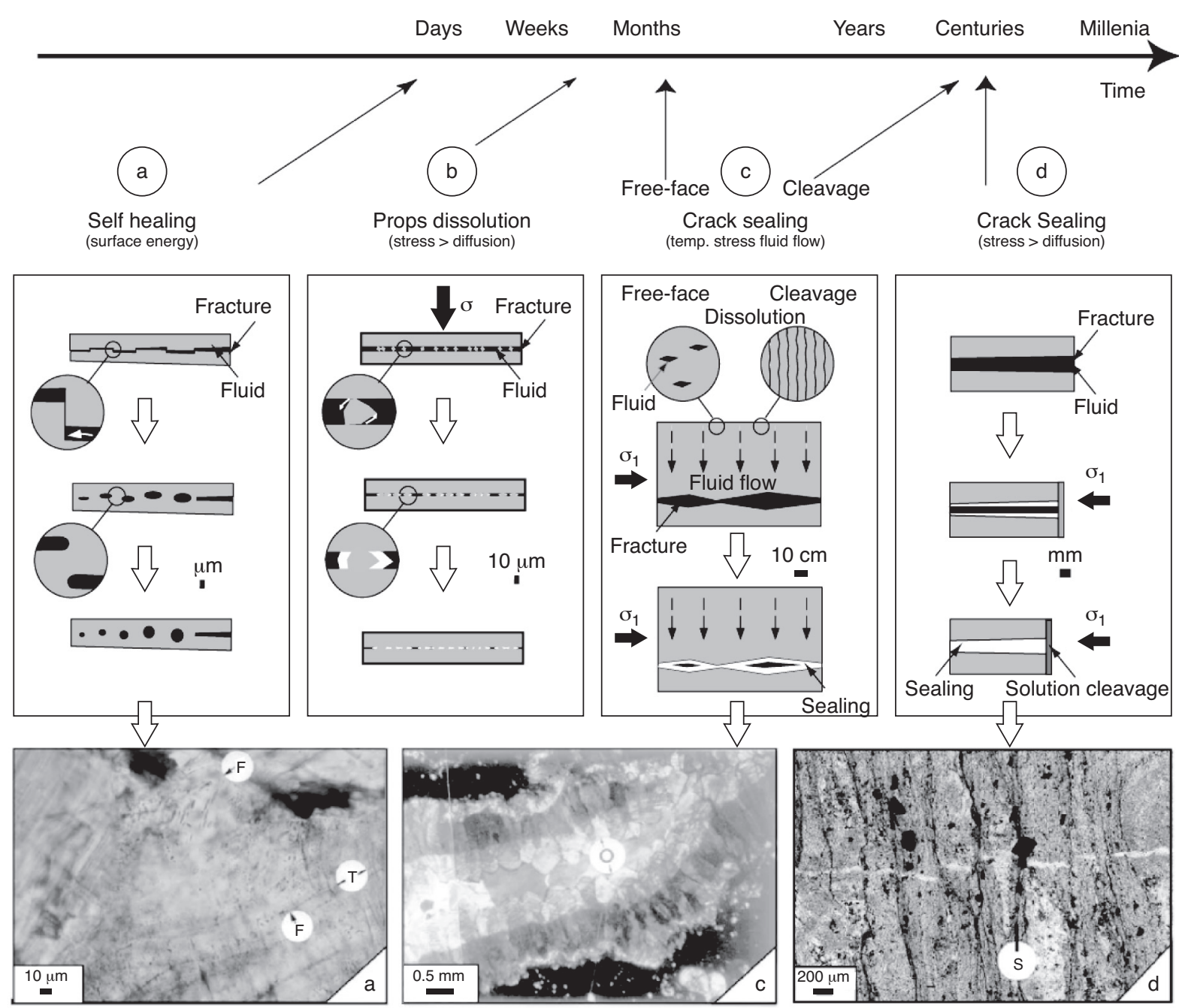

Figure 3

Various mechanisms of fault self-healing and sealing with characteristic times ranging from days to millennia: a) self-healing driven by surface energy; b) dissolution of props driven by stress and pore pressure decreases; c) crack sealing with fluid advection controlled either by free-face reaction rates in pores or by diffusion rates along solution cleavage seams; d) crack sealing driven by stress with mass transfer from solution cleavage to fracture. Adapted from Gratier and Gueydan (2007). Below, the photographs show these structures in their geological context.

- self-healing is driven by minimization of surface energy: Figure 3a. It may be rather fast (from days to months; see, for example, Brantley et al., 1990). However it is only relevant to very thin fractures (micrometer aperture) that keep solid-solid contacts in order to promote high surface energy sites (see enlargement Fig. 3a). Tenthorey et al. (2003) performed experiments at high temperature that show how hydrothermal reactions in faulted rocks lead to strength recovery and permeability decrease with a power dependence in time (exponent $=0.38$, Fig. $4 b$ ). Contact strengthening was observed by Dysthe et al. (2003) with a decrease in the interface roughness with displacement with also a power law (exponent $=0.33$ ). Niemeijer and
Spiers (2006) and Niemeijer et al. (2008) showed, in a simulated phyllosilicate/halite fault gouge, that an interface that has slipped seismically rapidly re-strengthens. All these experiments that have been done at a relatively fast strain rate (days to weeks) mostly attest to self-healing processes controlled by reaction rates with relatively high activation energy $\left(70 \mathrm{~kJ} / \mathrm{m} /{ }^{\circ}\right)$;

- dissolution of props trapped in fractures is driven by stress and a decrease in fluid pressure: Figure $3 b$. It may be done in the lab over time scales from weeks to months (Beeler and Hickmann, 2004). It is also a mechanism that is relevant to very thin fractures that collapse with sealing in a closed system. 


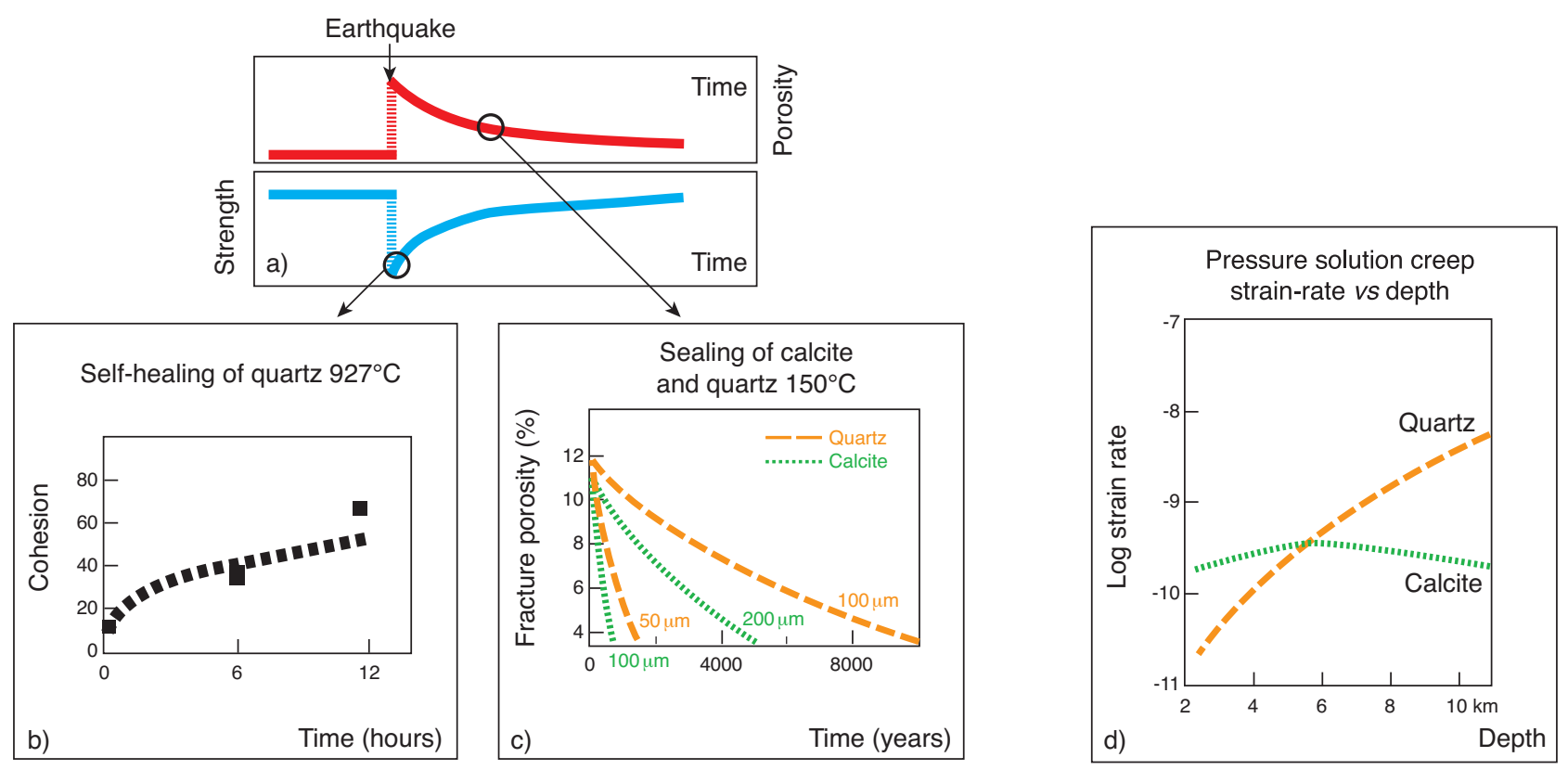

Figure 4

Mechanisms of fault strengthening: a) evolution of strength and porosity with time during fracturing and healing cycles; b) fast (hours, days) post-fracturing strengthening (cohesion) by quartz self-healing; c) modeling of non-steady-state crack sealing: the evolution with time depends on the nature of the minerals (quartz or calcite) and on the spacing between the fractures (parameter $d$ in $E q .4,5$ in the text). Adapted from Brenguier et al., 2007 (a), Tenthorey et al., 2003 (b), Gratier et al., 2003 (c). d) Inverse evolution of pressure solution creep strain-rates with depth $(\dot{\varepsilon}=\Delta d / d \Delta t)$ for quartz and calcite, due to the inverse evolution of their solubility with temperature, data from Gratier et al. (2009), with the same small distance of mass transfer ( $d=100$ micrometers in fault zone) using the creep equation:

$\dot{\varepsilon}=\Delta d / d \Delta t=8$ D.w.c. $V_{s} \cdot\left(e^{3 \sigma_{n} V_{s} / R T}-1\right) / d^{3}$ with, at $10 \mathrm{~km}, T=350^{\circ} \mathrm{C}, \sigma=60 \mathrm{MPa}$, at $3 \mathrm{~km} T=120^{\circ} \mathrm{C}, \sigma=18 \mathrm{MPa}$.

The sealing of large aperture cracks that constitute the numerous veins observed in fault zones and that require an input of matter from outside: Figures $3 \mathrm{c}$ and $3 \mathrm{~d}$ is much slower:

- crack sealing driven by stress, with mass transfer by diffusion from solution cleavage to fracture: Figure $3 \mathrm{~d}$ is the most commonly observed mechanism in fault zones (Gratier et al., 2003). This is both a mechanism of creep and of sealing. In natural deformation, this mechanism is most often controlled by the diffusion step $(E q .4,5)$ or by reaction rates that are slower than this diffusion rate due to the effects of growth-inhibiting impurity species present in the fluid (de Meer et al., 2000). Activation energy is relatively low $\left(10-15 \mathrm{~kJ} / \mathrm{m} /{ }^{\circ}\right.$, Rutter, 1976). The characteristic times of sealing range from years to centuries. Such a mechanism can be only reproduced in the lab when its kinetics is activated. This may be done by using a mineral with high solubility in water (Rutter, 1976), such as halite (Tada and Siever, 1986; Urai et al., 1986; Gratier, 1993; Hickman and Evans, 1991; Karcz et al., 2006), or by increasing the solubility of the solution (with $\mathrm{NaOH}$, for example, when using quartz, Gratier and Guiguet, 1986). The kinetics may also be activated by working at very high temperatures (Cox and Paterson, 1991). Moreover, as this sealing is associated with an increase in the surface of contact, and thus of the distance of mass transfer, its rate progressively decreases with time (see the effect of the parameter $d$ in Eq. 4, 5). This is true on a grain scale and this rules out the possibility of steady-state compaction rate. This aspect has been explored by Lehner (1995), for the simplest case of regular packing spheres. This is also true for episodically fractured rock (Fig. 4 c). An example of the modeling of the evolution of the sealing rate with time is given in Figure 4c (Renard et al., 2000; Gratier et al., 2003). Application to the modeling of transfer properties is discussed below. It must be noted that pressure solution strain rates varies with depth (effect of temperature and pressure) and minerals (effect of solubility and molar volume). Using creep relations deduced from indenter experiments (Gratier et al., 2009), and extending it to other mineral such as calcite, one may compare the evolution of the strain rate values of these two minerals with depth from 2 to $10 \mathrm{~km}$ (Fig. 4d) with the same constant value of the distance of mass transfer ( $d=100$ micrometers). One can see that the two minerals show opposite evolution of their pressure solution strain rates due to the inverse evolution of their solubility with the temperature. Calcite is more mobile than quartz at low temperature whereas quartz is more mobile than calcite at high temperature; 
- crack sealing with fluid infiltration: Figure $3 \mathrm{c}$, is controlled either by reactions on free faces $(E q .2,3)$, or by diffusion along solution cleavage $(E q .4,5)$. It is especially dependent on the controlling step in the zone of dissolution. Dissolution could occur along solution cleavage and as dissolved species must be extracted from trapped fluid under stress (Fig. 3c right), the controlling step is the same as above (Fig. $3 d$ ). It is most often controlled by diffusion or by reaction processes slower than the diffusion. Alternatively, if dissolution occurs on free fluid faces (Fig. 3c left) with the development of voids by the dissolution of some mineral (for example, the transformation of granite into episyenites), diffusion being relatively fast in free fluids, the process may be controlled by reaction kinetics, as is the case in the change in shape of fluid inclusions (Gratier and Jenatton, 1984). Consequently, characteristic times of crack sealing with fluid infiltration in natural deformation may range from months to centuries. It is not easy to distinguish between crack sealing with diffusion and crack sealing with infiltration. A general rule is that infiltration needing some open canal to occur, sealing with infiltration cannot completely fill a vein. So most often, this mechanism leaves some voids in veins with euhedral growth of crystals that attests to their growth in free fluids (Fig. 3c). Stable isotope studies can also give an indication of the size of the closed system. One can see, for example, the work of Marquer and Burkard (1992), who showed that the size of the closed system evolved during the deformation process:

- syntectonic veins with associated stylolites, within the Helvetic carbonate cover, have $\delta 180$ compositions depending on the adjacent wall rock compositions and varying with respect to the initial chemical heterogeneity of each sedimentary layer (closed systems),

- alternatively, variation profiles in major cover thrusts show a variable increase in $87 \mathrm{Sr} / 86 \mathrm{Sr}$ ratios combined with a strong decrease in $\delta 18 \mathrm{O}$ approaching an isotopic equilibrium with the basement rocks, indicating that the systems have been opened by large-scale fracturing processes linked to the major thrusts.

Therefore, and except for the self-healing process and for some advection processes with free-face dissolution, sealing processes are slow stress-driven processes linked to creep deformation. This can explain the link observed between the characteristic times of post-seismic strength and permeability recovery (Fig. la and 4a).

\subsection{Modeling Strength Evolution}

\subsubsection{Modeling the Friction Experiments by Rate-and-State Laws}

Rate-and-state constitutive laws for friction were introduced by Dietrich (1979, 1981), Ruina (1983) and Rice (Rice,
1983; Rice and Ruina, 1983). These laws are thoroughly discussed by Marone (1998). The concept relies on two types of observations. The first one is that static friction between two solids increases with time, even during stationary contact (hold time) (Fig. 5 a left). From various experiments, this corresponds to a time-dependent strengthening effect with logarithmic time dependence. The second observation is that sliding (dynamic) friction decreases with velocity for most rocks, a phenomenon known as velocity weakening (Fig. $5 \mathrm{a} \mathrm{right).}$ The rate-and-state law combines these two aspects (Scholz, 1998; Marone, 1998):

$$
\tau=\left[\mu_{o}+a \ln \left(V / V_{o}\right)+b \ln \left(V_{o} \theta / \mathrm{L}\right)\right] \bar{\sigma}
$$

where $\tau$ is shear stress, $\bar{\sigma}$ is effective normal stress, $V$ is slip velocity, $V_{o}$ a reference velocity, $\mu_{o}$ the steady-state friction coefficient at $V_{o}$, and $a$ and $b$ are material properties. $L$ is the critical slip distance. $\theta$ is a state variable that evolves according to Dietrich (1979):

$$
d \theta / d t=1-(\theta V / L)
$$

Other formulations of this evolution with time have been proposed by Ruina (1983) and Perrin et al. (1995) that are thoroughly discussed in Marone (1998). The significance of the terms is given in Figure 5b. This law has been used in order to model fault dynamics, such as slip instabilities (earthquakes), earthquake triggering by stress perturbations, post-seismic deformation, and slow earthquakes. It has been used extensively to model earthquakes (Dieterich, 1994), postseismic relaxation driven by brittle creep (Perfettini and Avouac, 2004, 2007) and landslides (Helmstetter et al., 2004), as well as other contexts (Heslot et al., 1994; Helmstetter and Shaw, 2006). The rate-and-state law is a conceptual approach that has only been measured for shortterm experiments (days - weeks). It remains to be demonstrated that it could be extended over geological time scales. Heat flow measurements along some faults as the San Andreas Fault constrain the coefficient of friction of the fault in the creeping section to a value smaller than 0.2 , well below values currently expected with friction (0.6). Friction may be linked to transitory post-seismic events (Johnson et al., 2006), however it is not likely to be a major mechanism for permanent creep.

\subsubsection{Modeling the Competition between Weakening and Strengthening Effects by Viscosity Evolution}

Moreover, if the rate-and-state law is well adapted to the modeling of the sliding surfaces, it is less clear how it can model the damage induced by earthquakes that can propagate far away from the gouge. The work of Pili et al. (1998) showed, from stable isotope studies that in active faults fluids flow from depth through a 1-2-km-wide damaged zone. Consequently, modeling the behavior of a large shear zone requires a different approach from rate-and-state law. Such an approach can rely on the modeling of viscosity evolution 


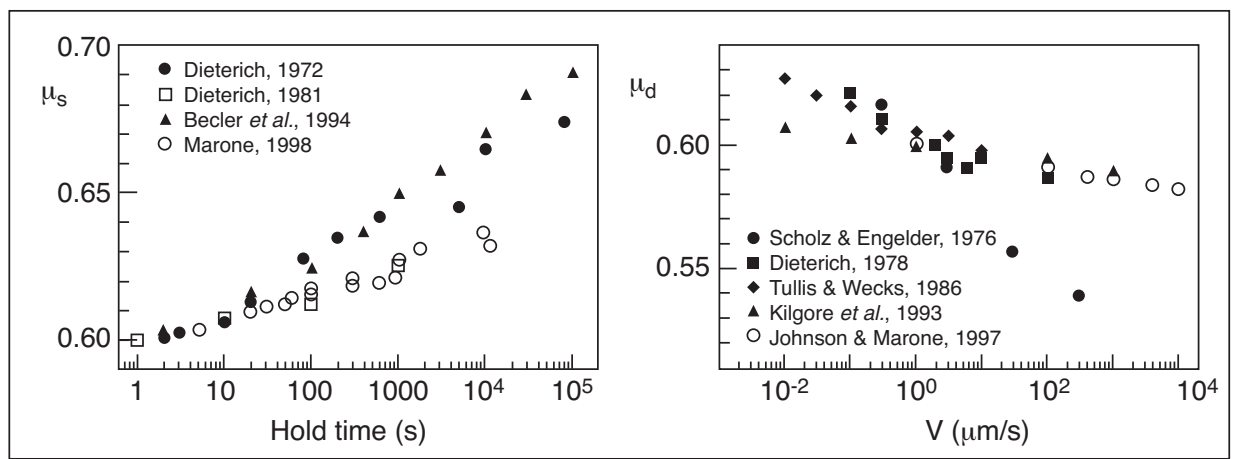

a)

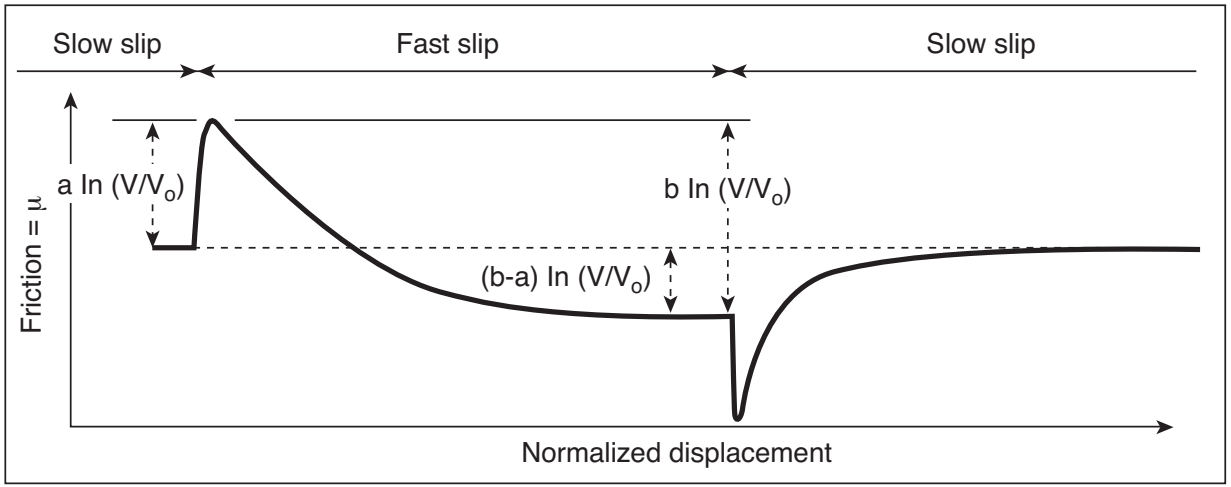

b)

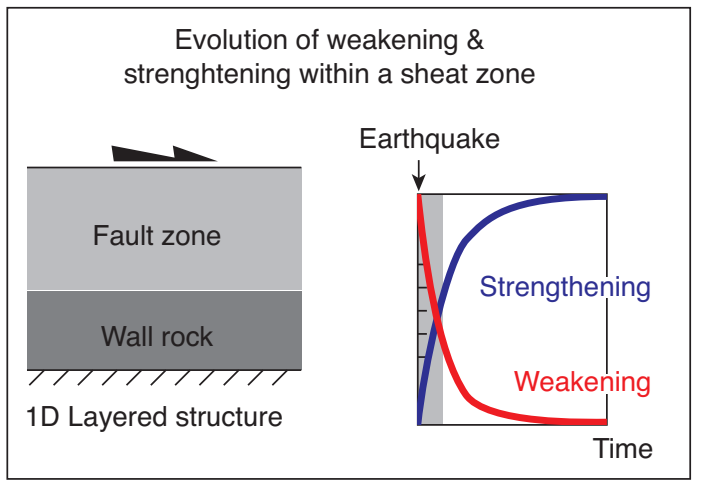

c)

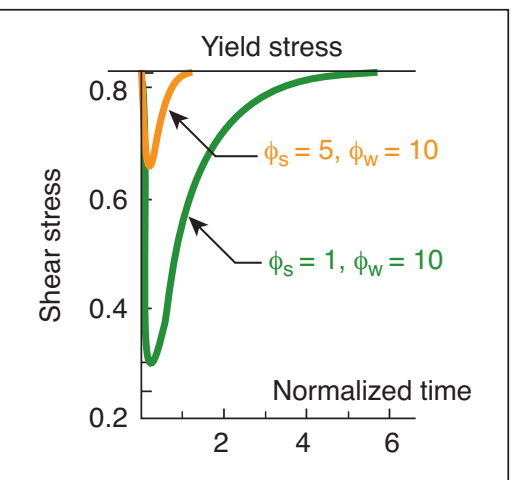

d)

Figure 5

a) Variations in static friction with different hold time values (left), evolution of dynamic friction with slip velocity (right); b) friction versus normalized displacement for a rate-and-state law, see Equations 6, 7 in the text; c) modeling of strength evolution in a fault zone when assuming a competition between weakening and strengthening processes; d) shear stress versus normalized time with various characteristic times of strengthening: relatively fast (orange) or relatively slow (green), see Equations 8 and 9 in the text. Adapted from Marone, 1998, (a, b) and Gratier and Gueydan, 2007, (c, d).

in which the strength of damaged zones instantaneously decreases then slowly increases with time after an earthquake. The characteristic time scales of weakening and strengthening differ and this difference strongly controls the rheology of active faults and thus influences the duration of seismic cycles. Simple rheological models have been proposed to account for these two effects (Gratier and Gueydan, 2007). The damaged zone is modeled as a ductile material, with constitutive rheological laws that involve pressure-solution creep, healing processes and reaction softening. These ductile mechanisms are assumed to be relevant within the whole seismogenic crust, as is suggested by the occurrence of pressure solution deformation patterns at all depths in the upper crust. A 1D model (SARPP 2003) is used (Fig. 5c) where an idealized damaged zone undergoes simple shear at constant velocity. The model is composed of a layered 
structure, in simple shearing (Fig. 5c), Gratier and Gueydan (2007). The fault zone is the region where weakening and strengthening will prevail, inducing a change with time in the viscosity $\eta(t)$. In contrast, the viscosity of the wall rock remains at its initial value $\eta_{0}$. So the viscosity $\eta(t)$ within the fault zone is changed by a competition between weakening and strengthening (Fig. 5c) as follows:

$$
\eta(t)=[w(t)+s(t)] \eta_{0}
$$

where $w(t), s(t)$ and $\eta_{o}$ define the amount of weakening, strengthening and the initial viscosity, respectively, with the $0<w(t)<1$ and $0<s(t)<1$.

The time evolution of the weakening $w(t)$ and strengthening $s(t)$ are governed by the following equations:

$$
\frac{\partial w}{\partial t}=\varphi_{w} \dot{\varepsilon}\left[w_{\infty}-w(t)\right] \text { and } \frac{\partial s}{\partial t}=\varphi_{s} \dot{\varepsilon}\left[s_{\infty}-s(t)\right]
$$

$w_{\infty}$ and $s_{\infty}$ define the total amount of weakening and strengthening. $\varphi_{w}$ and $\varphi_{s}$ define the kinetics of weakening and strengthening, and are free parameters that characterize the deformed material.

Preliminary results of this model show that the kinetics of the weakening and strengthening processes determine the relative rates of shear stress decrease and increase during the interseismic period. For example, in Figure 5d, everything being equal, faster kinetics for the strengthening processes induces shorter recovery times of the fault strength. The kinetics of dissolution precipitation and mineral reactions is therefore expected to be an important control on the healing time of active faults and possibly on the recurrence time of earthquakes.

\section{HOW DO PERMEABILITY AND PORE PRESSURE EVOLVE DURING THE "FRACTURING AND HEALING" CYCLE?}

\subsection{Change in Permeability}

We do not discuss here what happens during the main rupture. Zhu and Wong (1997) studied, for example, the evolution of porosity and permeability at the transition from brittle faulting to cataclastic deformation. They pointed out the various effects of both deviatoric and hydrostatic stresses. We simply consider that permeability in the gouge and damaged zone decreases during an earthquake, assuming that the post-seismic decrease in wave velocity attests to this effect (Fig. 1a). We know that fluids flow through faults in the upper crust, as shown, for example, by isotope studies or by the evidence of fluid-related aftershock sequences (Miller $e t$ al., 2004). The fluids come either from depth (i.e., from the mantle or lower crust along the San Andreas, Kennedy et al., 1997) or from the surface (i.e., from meteoric water along the Aegion Fault, Benedicto et al., 2008; Pizzino et al., 2004).
The pathways of the fluids localized along the fault are revealed by isotope studies of fluid inclusions trapped in veins (Pili et al., 1998, 2002). From these results, the fault gouge and the whole damaged zone (up to 1-2 km away from the principle slip surface near the San Andreas fault, for example) are infiltrated several times, in connection with several earthquakes. In contrast, each fracture is mostly opened and sealed once (in connection with a single earthquake). As seen above (Fig. 3), characteristic times of healing processes by mass transfer range from days to millennia, mostly depending on the aperture of the fractures (from microns to $\mathrm{cm})$. Consequently, modeling the post-seismic evolution of the permeability along the whole fault must integrate the effect of all the healing mechanisms. However, for each set of fractures associated with a specific mechanism of sealing, the sealing rate evolves with time. So, it is difficult to model the evolution of various sets of fractures with various characteristics times of sealing that evolve with time.

A first step is to try to evaluate a simple porosity versus time relation for each type of mechanism of fracture sealing. For example, Renard et al. (2000) modeled the evolution that the sealing rate achieves by pressure solution with mass transfer from solution cleavage to cracks. This mechanism appears to be one of the most important mechanisms for crack sealing and creep during post-seismic deformation Figure $3 \mathrm{~d}$. The sealing rate decreases with time due to two combined effects (Fig. 6b): the progressive increase in the distance of mass transfer (parameter $d$ in Eq. 4, 5) and the increase in dissolution surface under stress that reduces the driving forces (parameter $\sigma_{n}$ in $E q .4,5$ ). Taking into account this geometric evolution the porosity $\phi$ is modeled to decay exponentially with time and space (Fig. 4c), Gratier et al. (2003):

$$
\phi=\phi_{0} e^{-x / L} e^{-t / \tau(z)}
$$

$L$ is the characteristic distance for the exponential decrease in the porosity after each earthquake (distance for which the maximum porosity $\phi_{0}$ along the fault is divided by 2.72). $\tau(z)$ is the characteristic time of the sealing process (time during which the porosity is divided by 2.72 ). With such a very simple relation, the characteristic time of the sealing process expresses the sealing rate evolution with time for a given geological context. Evolution of such a parameter with depth may be derived from both experiments and observations of natural samples. Examples are given in Figure 6 of the $\tau(z)$ evolution with depth for a stratified crust near the San Andreas Fault with different rates of compaction depending on both the main soluble species (calcite or quartz) and the PT evolution. Following Lockner and Evans (1995), the relation between permeability $k$ and porosity $\phi$ is expressed as $k \approx \phi^{3}$. Such an evolution was used to model the evolution of pore pressure within the fault; see Figure 6 .

A second step is to find a way to integrate the various scales of time and space during the fault healing process. The 


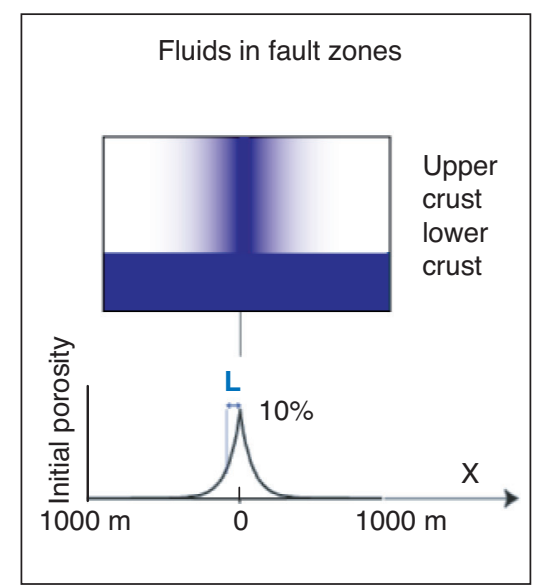

a)

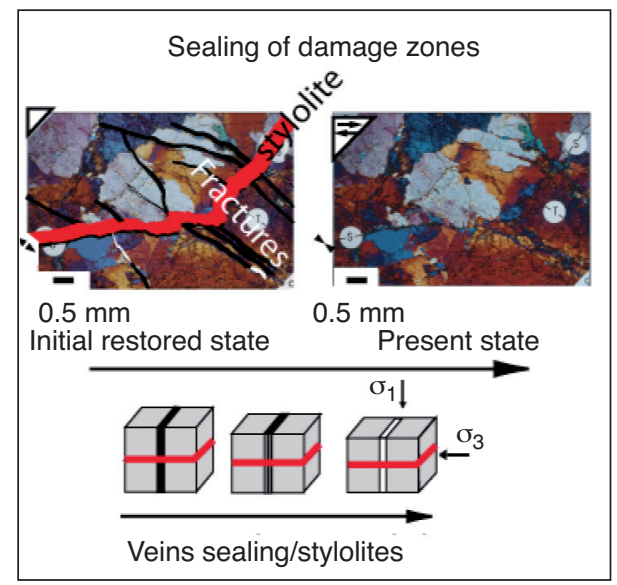

b)

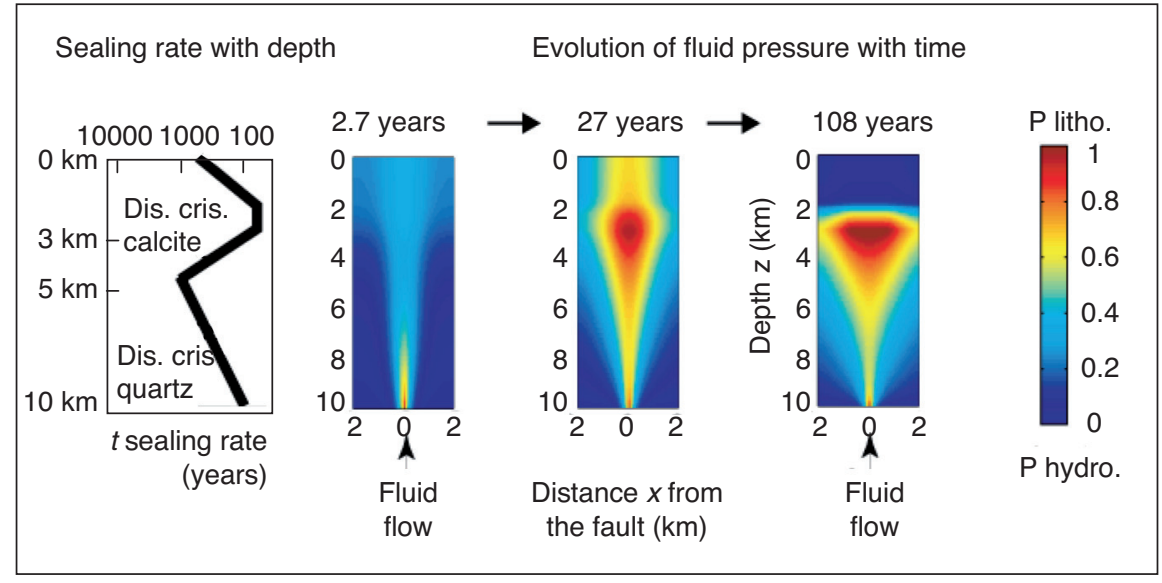

c)

Figure 6

a) Fluids in fault zone (blue) with associated evolution of porosity (below); b) modeling of pressure solution crack sealing rate in the damaged zone when considering the effect of the progressive sealing of fracture network by pressure solution: dissolution surfaces (stylolites) are red, initial fractures filled with fluid are black, sealing is white; c) modeling of pore pressure evolution in a fault zone during the inter-seismic period, when integrating over the upper crust the difference in sealing kinetics between quartz and calcite. Adapted from Gratier et al., 2003, (a, c) and Renard et al., 2000, (b).

use of the percolation theory and the simulation of random networks are possibilities that have been successfully explored by Zhu et al. (1995) in order to analyze the evolution of permeability with a random shrinkage model and a connectivity loss model in a three-dimensional cubic network. Their simulations predict the changes in permeability and porosity obtained from hot-pressed calcite and quartz experiments. It is a step toward a general model of permeability evolution within the whole natural fault zone.

Finally, one may consider another question: does fracturing develop during the interseismic period? It is not easy to answer such a question because it is not easy to distinguish co-seismic fracture from subcritical fracture that could develop during the interseismic period. Olson et al. (2009) showed that it is possible to sustain opening-mode fracture growth with sub-lithostatic pore pressure, leading to competition between mineral precipitation and the fracture opening rate that determines how the fracture network is progressively sealed.

\subsection{Change in Pore Pressure}

Another problem arises in natural fault zones. If fluid inflow is significant, this can increase pore fluid pressure and reduce effective shear strength, at least locally within the fault. During the interseismic period, the combined effect of the strengthening linked to the sealing process and of the increasing pore pressure sets the stage for stress building and seismicity. The characteristic time of pore fluid change is even more difficult to estimate than the characteristic time of the 
sealing since it relies on both the flux of fluid from depth (Rice, 1992) and on the possible compaction of the whole fault (Sleep and Blanpied, 1992), or on both the flux of fluid from depth and the sealing rate (Gratier et al., 2003). Modeling the permeability evolution in gouges and damaged zones shows that gouges must seal faster than damaged zones due to the thinner aperture and lower size of their fractures. An example is given in Figure 6 where the limiting process of the rate of permeability change is considered to be the slowest sealing rate within the damaged zone around the gouge. The sealing rate is modeled to decay exponentially with time (after the earthquake) and space (away from the main seismic slip zone), relation 10 (Fig. 6a). Over-pressuring (lithostatic pressure) develops at two different depth intervals (Fig. 6c). Firstly, at depth (bottom of the seismic crust) due to the combined effects of localized inflow of fluid from the lower crust and the presence of quartz that sealed the veins, increasing the pore pressure. Secondly, in the upper part of the crust, where the high solubility of calcite renders this mineral available for mass transfer and relatively fast sealing of the veins. A comparison of the evolution of the pressure solution rates with depth for the two minerals is given in Figure 4d. One may finally notice that the time of significant pore pressure change (time to reach local sublithostatic pressure of significant size) is of the order of magnitude of the time intervals between earthquakes (tens to hundreds years).

\section{CONCLUSIONS, WHAT TO DO NEXT}

Fault permeability and strength evolve with time during fracturing and healing cycles related to post-fracturing creep and sealing processes. Laboratory experiments and observations of natural faults show how non-steady-state pressure solution processes explain both creep and sealing processes. Consequently, the duration of the fracturing and sealing cycle should be related to some extent to the geological context of a faulted area. Some leads are presented here that could be followed or developed in the future in order to model best the characteristic times of fracturing and sealing cycles depending on the geological context.

\section{Reproducing the Right Mechanism in the Lab}

The need for reproducing the actual transfer mechanism is very important since the various mechanisms of mass transfer (self-healing or sealing) have neither the same characteristic times nor the same sensitivity to thermodynamic parameters. For example, kinetics of self-healing processes that are fast enough to be reproduced easily in the lab (hours days) are most often controlled by reaction rates with high activation energy (high dependence on the temperature). Conversely, sealing processes, that are always very slow and difficult to reproduce in the lab (months or years), are mostly controlled by diffusion, with low activation energy. Both must be reproduced in the lab and the relative part of each mechanism must be evaluated from the observation of natural systems and integrated in modeling.

Evaluating the Parameters of the Creep and Sealing Laws Modeling the evolution of transfer and rheological properties implies knowing both the fundamental mechanism of creep and sealing and the values of the parameters of the creep and sealing laws. For example, investigating the pressure solution mechanism with diffusion as the limiting process $(E q .4,5)$ implies first choosing a model of evolution (Fig. $6 b$ ) then evaluating two types of parameters:

- some parameters must be evaluated from experiments as kinetics parameters $(D w=$ diffusion coefficient time thickness of the diffusion path) or the effect of stress (power or exponential effect), and;

- other parameters must be evaluated from the observations of natural samples such as the effect of the nature of fluid and minerals (solubility, molar volume) and the effect of the geometry of the path of mass transfer (for example, $d=$ mean distance of mass transfer along the thin fluid paths trapped under stress).

\section{Evaluating the Duration of the Fracturing and Sealing \\ Process in the Field}

Evaluating such duration in the field is also a major task. Piper et al. (2007) successfully demonstrated the potential of travertine that precipitated over a fault, as fossil records of geomagnetic paleo-secular variations, environmental change and earthquake activity. Coupled U/Th dating and magnetic studies could give both the duration of inter-seismic periods and the evolution of the fluid flux with time, at least for earthquakes of magnitude higher than 6-7. The problem is to be sure that the evolution of the travertine deposition is well connected with the evolution of fluid flow through faults at depth. This could rely on stable isotope measurements that help to evaluate the origin and the path of the fluids.

\section{Evaluating the Evolution of Transfer Properties \\ on the Scale of an Oil Reservoir}

Earthquakes have been observed to affect regional permeability (Rojstaczer and Wolf, 1992; Muir-Wood and King, 1993). Elkhoury et al. (2006) used the response of water well level to tidal-induced deformation to show that seismic waves increase the permeability. The change is shown to be proportional to the peak ground velocity and the effect may last several years. It could be interesting to collect data from oil reservoir exploitation in order to test this idea of permeability change within reservoirs affected by earthquakes, and especially to evaluate the characteristic times of healing that, according to our idea, must depend on the geological characteristics of the reservoir.

\section{Modeling the Complexity of the Evolution}

As stated above, modeling the evolution of the transfer and rheological properties from creep and sealing laws is only part 
of the problem. One also needs to integrate the slow evolution of fluid flux and pore fluid pressure along and near the fault. So the modeling must integrate mechanical, geochemical and hydrological aspects. The results predict the post-fracturing characteristic time scales of strength and transfer recovery in active faults, depending on the conditions of the deformation (nature of fluid and rocks, temperature, stress, strain rate, etc.). We expect that the complex interactions among these recovery time scales have a strong effect on the fracturing and healing cycle durations and on earthquake recurrence time, and that these time scales are characteristic of the geological and geodynamical context of a given region.

\section{ACKNOWLEDGMENTS}

I would like to thank two anonymous reviewers for their interesting suggestions and J. Richard, E. Frery, S. Mittempergher, F. Renard, F. Gueydan, D. Amitrano, D. Bernard, A-M. Boullier, G. Di Toro, H. Perfettini, C. Aubourg, M-L. Doan, A. Helmstetter, M. Bouchon, N. Ellouz-Zimmermann, V. Gardien, L. Jenatton, E. Larose, B. Vial, for helpful discussions. The project has been supported by the INSU-CNRS (aléas, risques et catastrophes naturels) and the LGIT lab.

\section{REFERENCES}

Andreani M., Boullier A.-M., Gratier J.-P. (2005) Development of schistosity by dissolution-crystallization in a Californian serpentinite gouge, J. Struct. Geol. 27, 2256-2267.

Bazin B., Bieber M.T., Roque C., Bouteca M. (1996) Improvement in the characterization of the acid wormholing by in-situ Xray CT visualizations, International Symposium on Formation Damage Control, Lafayette Louisiana USA, SPE paper 31073.

Beeler N.M., Hickman S.H. (2004) Stress-induced, time-dependent fracture closure at hydrothermal conditions, J. Geophys. Res. 109, B02211, doi: 10.1029/2002JB001782.

Bérest P., Blum P.A., Charpentier J.P., Gharbi H., Valès F. (2004) Fluage du sel gemme sous très faibles charges, creep of rock salt under very small loadings, C.R. Geosciences 336, 15, 1337-1344.

Benedicto A., Plagnes V., Vergély P., Flotté N., Schultz R.A. (2008) Fault and fluid interactions in a rifted margin: integrated study of calcite-sealed fault-related structures (southern Corinth margin), Geol. Soc. London, Spec. Pub. 299, 257-275.

Boullier A.-M., Fujimoto K., Ito H., Ohtani T., Keulen N., Fabbri O., Amitrano D., Dubois M., Pezard P. (2004) Structural evolution of the Nojima fault (Awaji Island, Japan) revisited from the GSJ drill hole at Hirabayashi, Earth Planets Space 56, 1233-1240.

Bourouis S., Cornet F.H. (2009) Microseismic activity and fluid fault interactions: some results from the Corinth Rift Laboratory (CRL), Greece, Geophys. J. Int. 178, 561-580, doi: 10.1111/j.1365246X.2009.04148.x.

Bouvier J.D., Kaarssijpesteijn C.H., Kluesner D.F., Onyejekwe C.C., Vanderpal R.C. (1989) 3 dimentional seismic interpretation and fault sealing investigation, Nun river field, Nigeria, AAPG Bull. 73, 1397-1414.

Brantley S., Evans B., Hickman S.H., Crerar D.A. (1990) Healing of microcracks in quartz: implications for fluid flow, Geology $\mathbf{1 8}$, 136-139.
Brenguier F., Campillo M., Hadziioannou C., Shapiro N.M., Nadeau R.M., Larose E. (2008) Postseismic relaxation along the San Andreas fault in the Parkfield area investigated with continuous seismological observations, Science 321, 1478-1481.

Bretan P., Yielding G., Jones H. (2003) Using calibrated shale gouge ratio to estimate hydrocarbon column heights, AAPG Bull. 87, 397-413.

Cox S.F., Paterson M.S. (1991) Experimental dissolution-precipitation creep in quartz aggregates at high-temperatures, Geophys. Res. Lett. 18, 1401-1404.

De Meer S., Spiers C.J., Peach C.J. (2000) Kinetics of precipitation of gypsum and implications for pressure-solution creep, J. Geol. Soc. London 157, 269-281.

Dewers T., Ortoleva P. (1990) A coupled reaction/transport/ mechanical model for intergranular pressure solution stylolites, and differential compaction and cementation in clean sandstones, Geochim. Cosmochim. Ac. 54, 1609-1625.

Dietrich J.H. (1979) Modeling of rock friction 1 experimental results and constitutive equations, J. Geophys. Res. 84, 2161-2168. Dieterich J.H. (1981) Constitutive properties of faults with simulated gouge, in Mechanical Behavior of Crustal Rocks, Carter N.L., Friedman M., Logan J.M., Sterns D.W. (eds.), Am. Geophys. Union Monogr. 24, 103-120.

Dieterich J.H. (1994) A constitutive law for rate of earthquake production and its application to earthquake clustering, J. Geophys. Res. 99, 2601-2618.

Doan M.-L., Brodsky E.E., Kano Y., Ma K.-F. (2006) In situ measurements of the hydraulic diffusivity of the active Chelungpu fault Taiwan, Geophys. Res. Lett. 33, 16.

Evans J.P., Chester F.M. (1995) Fluid-rock interaction in faults of the San Andreas system: inference from the San Gabriel fault rock geochemistry, J. Geophys. Res. 100, 13,007-13,020.

Freed A.M. (2007) After slip (and only after slip) following the 2004 Parkfield, California earthquake, Geophys. Res. Lett. 34, LO6312, doi: 101029/2006GL029155.

Fisher Q.J., Knipe R.J. (2001) The permeability of faults within siliciclastic petroleum reservoirs of the North Sea and Norwegian Continental Shelf, Mar. Petrol. Geol. 18, 1063-1081.

Dysthe K., Renard F., Feder J., Jamtveit B., Meakin P., Jøssang T. (2003) High resolution measurements of pressure solution creep, Phys. Rev. E 68, 011603, doi: 10.1103/PhysRevE.68.011603.

Elkhoury J.E., Brodsky E.E., Agnew D.A. (2006) Seismic waves increase permeability, Nature 441, 1135-1138, doi: 10.1038/ nature04798.

Gratier J.-P., Vialon P. (1980) Deformation pattern in a heterogeneous material, folded and cleaved sedimentary cover immediately overlying a crystalline basement (Oisans, French Alps), Tectonophysics 65, 151-180.

Gratier J.-P., Jenatton L. (1984) Deformation by solution - deposition and reequilibration of fluid inclusions in crystals depending on temperature, internal pressure and stress, J. Struct. Geol. 5, 329-339. Gratier J.-P., Guiguet R. (1986) Experimental pressure solution deposition on quartz grains, the crucial effect of the nature of the fluid, J. Struct. Geol. 8, 845-56.

Gratier J.-P. (1993) Experimental pressure solution of halite by an indenter technique, Geophys. Res. Lett. 20, 1647-1650.

Gratier J.-P., Renard F., Labaume P. (1999) How pressure solution and fractures interact in the upper crust to make it behave in both a brittle and viscous manner, J. Struct. Geol. 21, 1189-1197.

Gratier J.-P., Favreau P., Renard F. (2003) Modeling fluid transfer along Californian faults when integrating pressure solution crack sealing and compaction process, J. Geophys. Res. 108, 28-52.

Gratier J.-P., Gueydan F. (2007) Deformation in the presence of fluids and mineral reactions: effect of fracturing and fluid-rocks interaction on seismic cycle, in Tectonic Faults, agent of change on a dynamic earth, Handy M.R., Hirth G., Hovius N. (eds.), Dahlem Workshop, The MIT Press, Cambridge, Mass., USA, pp. 319-356. 
Gratier J.-P., Guiguet R., Renard F., Jenatton L. (2009) A pressure solution creep law for quartz from indentation experiments, $J$. Geophys. Res. 114, B03403, doi: 10.1029/2008JB005652.

Guéguen Y., Palciauskas V. (1994) Introduction to the physics of rocks, Princeton University Press editor, 299 p.

Gueydan F., Leroy Y.M., Jolivet L., Agard P. (2003) Analysis of continental midcrustal strain localization induced by reaction-softening and microfracturing, J. Geophys. Res. 108, 2064, doi: 10.1029/2001JB000611.

Handy M.R. (1989) Deformation regime and the rheological evolution of fault zones in the lithosphere. The effect of pressure, temperature, grain size and time, Tectonophysics 163, 119-159.

Handy M.R., Hirth G., Hovius N. (2007) Introduction, Tectonic fault, in Tectonic faults agent of change on dynamic earth, Handy M.R., Hirth G., Hovius N. (eds.), Dahlem Workshop, The MIT Press, Cambridge, Mass., USA, pp. 1-8.

Hellmann R., Gratier J.-P., Chen T. (1998) Mineral-water interactions and stress: pressure solution of halite aggregates, Water Rock Interaction 9, 777-780.

Hellmann R., Renders P.J.N., Gratier J.-P., Guiguet R. (2002) Experimental pressure solution compaction of chalk in aqueous solutions. Part 1. Deformation behavior and chemistry, in WaterRock Interactions, Ore Deposits, and Environmental Geochemistry: A tribute to David A. Crerar, Hellmann R., Wood S.A. (eds.), Geochemical Society, pp. 129-152.

Helmstetter A., Sornette D., Grasso J.-R., Andersen J.V., Gluzman S., Pisarenko V. (2004) Slider-block friction model for landslides: implication for prediction of mountain collapse, J. Geophys. Res. 109, B02409, doi: 10.1029/2002JB002160.

Helmstetter A., Shaw B.E. (2007) Relation between stress heterogeneity and aftershock rate in the rate-and-state model, J. Geophys. Res. 111, B07304, doi: 10.1029/2005JB004077.

Heslot F., Baumberger T., Perrin B., Caroli B., Caroli C. (1994) Creep, stick-slip, and dry-friction dynamics: Experiments and a heuristic model, Phys. Rev. E, 49, 4973-4988.

Hickman S.H., Evans B. (1991) Experimental pressure solution in halite: the effect of grain/ interphase boundary structure, J. Geol. Soc. London 148, 549-560.

Johnson K.M., Bürgmann R., Larson K. (2006) Frictional properties on the San Andreas Fault near Parkfield, California, inferred from models of afterslip following the 2004 earthquake, B. Seismol. Soc. Am. 96, S321-S338.

Karcz Z., Aharonov E., Ertas D., Polizzotti R., Scholz C.H. (2006) Stability of a sodium chloride indenter contact undergoing pressure solution, Geology 34, 61-63, doi: 10.1130/G21722.1.

Kennedy B.M., Kharaka Y.K., Evans W.C., Ellwood A., De Paolo D.J., Thordsen J., Ambats G. Mariner R.H. (1997) Mantle fluids in the San Andreas fault system, California, Science 278, 1278-1280.

Kitagawa Y., Fujimori K., Koizumi N. (2002) Temporal change in permeability of the rocks estimated from repeated water injection experiments near the Nojima fault in Awaji Island Japan, Geophys. Res. Lett. 29, doi: 10.1029/2001GL014030.

Knipe R.J. (1992) Faulting processes and fault seal, in Faulting and fault sealing and fluid flow in hydrocarbon reservoirs, Jones G., Fisher Q.J., Knipe R.J. (eds.), Geological Society London Special Publication 147, 325-342.

Labaume P., Moretti I. (2001) Diagenesis-dependence of cataclastic thrust fault zone sealing in sandstones. Example from the Bolivian Sub-Andean Zone, J. Struct. Geol. 23, 1659-1675.

Labaume P., Carrio-Schaffhauser E., Gamond J.F., Renard F. (2004) Deformation mechanisms and fluid-driven mass transfers in the recent fault zones of the Corinth Rift (Greece), C.R. Acad. Sci. 336, 4-5, 375-383.

Lehner F.K. (1995) A model for intergranular pressure solution in open systems, Tectonophysics 245, 153-170.
Leroy Y.M., Heidug W.K. (1994) Geometrical evolution of stressed and curved solid-fluid phase boundaries 2. Stability of cylindrical pores, J. Geophys. Res. 99, 517-530.

Le Guen Y., Renard F., Hellmann R., Brosse E., Collombet M., Tisserand D., Gratier J.-P. (2007) Enhanced deformation of limestone and sandstone in the presence of high $\mathrm{pC}_{2}$ fluids, J. Geophys. Res. 112, B05421, doi: 10.1029/2006JB004637.

Li Y.G., Vidale J.E., Day S.M., Oglesby D.D., Cochran E. (2003) Postseismic fault healing on the rupture zone of the 1999 M 7.1 Hector Mine, California, earthquake, B. Seismol. Soc. Am. 93, 854869.

Li Y.G., Po Chen E., Cochran E., Vidale J.E. (2007) Seismic velocity variations on the San Andreas fault caused by the 2004 M6 Parkfield Earthquake and their implication, Earth Planets Space 59, 21-31.

Lockner D., Evans B. (1995) Densification of quartz powder and reduction of conductivity at $700^{\circ} \mathrm{C}, J$. Geophys. Res. 100, 1308113092.

Lockner D.A., Tanaka H., Ito H., Ikeda R., Omura K., Naka H. (2009) Geometry of the Nojima Fault at Nojima-Hirabayashi, Japan - I. A Simple Damage Structure Inferred from Borehole Core Permeability, Pure Appl. Geophys. 166, 1649-1667, doi: 10.1007/s00024-009-0515-0.

Marquer D., Burkhard M. (1992) Fluid circulation, progressive deformation and mass-transfer processes in the upper crust: the example of basement-cover relationships in the external crystalline massifs, Switzerland, J. Struct. Geol. 14, 1047-1057.

Marone C. (1998) Laboratory-derived friction laws and their application to seismic faulting, Annu. Rev. Earth Pl.Sc. 26, 643-696.

McEwen T.J. (1978) Diffusional mass transfer process in pitted pebble conglomerates, Contrib. Mineral. Petr. 67, 405-415.

Miller S.A., Collettini C., Chiaraluce L., Cocco M., Barchi M., Kaus B.J.P. (2004) Aftershocks driven by a high-pressure $\mathrm{CO}_{2}$ source at depth, Nature 427, 724-727.

Moore D.E. Lockner D.A., Ito H., Ikeda R., Tanaka H., Omura K. (2009) Geometry of the Nojima Fault at Nojima-Hirabayashi, Japan - II. Microstructures and their Implications for Permeability and Strength, Pure Appl. Geophys. 166, 1669-1691, doi: 10.1007/s00024-009-0513-2.

Muir-Wood R., King G. (1993) Hydrological signatures of earthquake strain, J. Geophys. Res. 98, 22035-22068.

Niemeijer A.R., Spiers C.J. (2006) Velocity dependence of strength and healing behaviour in simulated phyllosilicate-bearing fault gouge, Tectonophysics 427, 231-253.

Niemeijer A.R., Marone C., Elsworth D. (2008) Healing of simulated fault gouges aided by pressure solution: results from rock analogue experiments, J. Geophys. Res. 113, B04204, doi: 101029/2007JB005376.

Olson J.E., Laubach S.E., Lander R.H. (2009) Natural fracture characterization in tight gas sandstones: integrating mechanics and diagenesis, Am. Ass. Petrol. Bull.93, 1-15.

Ortoleva P. (1994) Geochemical self-organization, Oxford University press, $411 \mathrm{p}$.

Paterson M.S. (2001) Relating experimental and geological rheology, Int. J. Earth Sci. 90, 157-167.

Perrin G., Rice J.R., Zheng G. (1995) Self-healing slip pulse on a frictional surface, J. Mech. Phys. Solids 43, 1461-1495.

Perfettini H., Avouac J.-P. (2004) Postseismic relaxation driven by brittle creep: A possible mechanism to reconcile geodetic measurements and the decay rate of aftershocks, application to the Chi-Chi earthquake, Taiwan, J. Geophys. Res. 109, B02304, doi: 10.1029/2003JB002488.

Perfettini H., Avouac J.-P. (2007) Modeling afterslip and aftershocks following the 1992 Landers earthquake, J. Geophys. Res. 112, B07409, doi: 10.1029/2006JB004399. 
Person M., Baumgartner L.P., Bos B., Connoly J.A.D., Gratier J.-P., Gueydan F., Miller S.A., Rosenberg C.L., Urai J.L., Yardley B.W.D. (2007) Fluids, Geochemical cycles and mass transport in fault zones, in Tectonics faults: agents of change on a dynamic earth, Handy M.R., Hirth G., Hovius N. (eds.), Dahlem Workshop, The MIT Press, Cambridge, Mass., USA. pp. 403-426.

Pfiffner O.A., Ramsay J.G. (1982) Constraints on geological rate: arguments from finite strain values of naturally deformed rocks, $J$. Geophys. Res. 87, 311-321.

Pili E.B., Kennedy B.M., Conrad M.S., Gratier J.-P. (1998) Isotope constraints on the involvement of fluids in the San Andreas fault, Eos Trans. AGU 79, 17, S229-S320, Spring meeting.

Pili E., Poitrasson F., Gratier J.-P. (2002) Geochemical constraints on how fluids get into and out of faulted limestones from the San Andreas Fault system: the role of host rocks in feeding dynamically organized fracture networks, Chem. Geol. 190, 231-250.

Piper J.D.A., Mesci L.B., Gürsoy H., Tatar O., Davies C.J. (2007) Paleomagnetic and rock magnetic properties of travertine: Its potential as a recorder of geomagnetic paleosecular variation, environmental change and earthquake activity in the Sicak Cermik geothermal field, Turkey, Phys. Chem. Earth 161, 50-73.

Pizzino L., Quattrocchi F., Cinti D., Galli G. (2004) Fluid geochemistry along the Eliki and Aigion seismogenic segments (Gulf of Corinth, Greece), C.R. Acad. Sci.336, 367-374.

Prioul N., Cornet F.H., Dorbath C., Dorbath L., Ogena M., Ramos E. (2000) An induced seismicity experiment across a creeping segment of the Philippine Fault, J. Geophys. Res. 105, 13595-13612.

Raj R. (1982) Creep in polycristalline aggregates by matter transport through a liquid phase, J. Geophys. Res. 87, 4731-4739.

Reid H.F. (1910) The mechanics of the earthquake, in The California Earthquake of April 18, 1906 Report of the State Earthquake Investigation commission, Vol. 2, Carnegie Institute Washington Publ. 87, 192 p.

Renard F., Gratier J.-P., Ortoleva P., Brosse E., Bazin B. (1998) Experimental evidence for self-organization during reactive fluid flow in a porous medium, Geophys. Res. Lett. 25, 385-388.

Renard F., Gratier J.-P., Jamveit B. (2000) Kinetics of crack-sealing, intergranular pressure solution and compaction around active faults, J. Struct. Geol. 22, 1395-1407.

Renard F., Bernard D., Thibault X., Boller E. (2004) Synchrotron 3D microtomography of halite aggregates during experimental pressure solution creep and evolution of the permeability, Geophys. Res. Lett. 31, L07607, doi: 10.1029/2004GL019605.

Rice J.R. (1983) Constitutive relations for faults slip and earthquake instabilities, Pure Appl. Geophys. 121, 443-475.

Rice J.R., Ruina A.L. (1983) Stability of steady frictional slipping, J. Appl. Mech. 105, 343-349.

Rice J.R. (1992) Fault stress states, pore pressure distributions, and the weakness of the San Andreas fault, in Fault Mechanics and Transport Properties of Rocks, Academic Press, pp. 475-503.

Rojstaczer S., Wolf S. (1992) Permeability changes associated with large earthquakes an example from Loma Prieta California, Geology 20, 211-214.

Ruina A. (1983) Slip instability and state variable friction laws, J. Geophys. Res. 88, 10359-10370.
Rutter E.H. (1976) The kinetics of rock deformation by pressure solution, Philos. T. Roy. Soc. London 283, 203-219.

SARPP (2003) Structural Analysis and Rock Physics Program, Leroy Y.M. and Gueydan F., LMS, École Polytechnique, France.

Scholz C.H. (1998) Earthquakes and friction laws, Nature 391, 37-42.

Sibson R.H., Robert F., Poulsen H.H.A.F. (1988) High Angle Faults, Fluid Pressure Cycling and Mesothermal Gold-Quartz Deposits, Geology 16, 551-555.

Sleep N.H., Blanpied M.L. (1994) Ductile creep and compaction: a mechanism for transiently increasing fluid pressure in mostly sealed fault zones, Pure Appl. Geophys. 143, 9-40.

Spiers C.J.S., De Meer S., Niemeijer A.R., Zhang X. (2004), Kinetics of rock deformation by pressure solution and the role of thin aqueous films, in Physisochemistry of water in geological and biological systems: structures and properties of thin aquous films, Frontiers Sci. Ser., Vol. 44, Nakashima S. et al. (eds.), pp. 129-158, Univ. Acad. Press, Tokyo.

Sykes L.R., Menke W. (2006) Repeat times of large earthquakes: Implications for earthquake mechanics and long-term prediction, $B$. Seismol. Soc. Am. 96, 1569-1596.

Tada R., Siever R. (1986) Experimental knife-edge pressure solution of halite, Geochim. Cosmochim. Ac. 50, 29-36.

Tenthorey E., Cox S.F., Todd H.F. (2003) Evolution of strength recovery and permeability during fluid-rock reaction in experimental fault zones, Earth Planet. Sc. Lett. 206, 161-172.

Titus S.J., DeMets C., Tikoff B. (2006) Thirty-five-year creep rates for the creeping segment of the San Andreas fault and the effects of the 2004 Parkfield earthquake: Constraints from alignment arrays, continuous global positioning system, and creepmeters, B. Seismol. Soc. Am. 96, S250-S268, doi: 10.1785/0120050811.

Urai J.L., Spiers C.J., Zwart H.J., Lister G.S. (1986) Weakening of rock-salt by water during long-term creep, Nature 324, 554-557.

Weyl P.K. (1959) Pressure solution and the force of crystallization: a phenomenological theory, J. Geophys. Res. 64, 2001-2025.

Worthington S.R.H., Ford D.C. (2009) Self-Organized Permeability in Carbonate Aquifers, Ground Water 47, 326-336.

Zhu W., David C., Wong T. (1995) Network modeling of permeability evolution during cementation and hot isostatic pressing, $J$. Geophys. Res. 100, 15,451-15,464.

Zhu W., Wong T. (1997) The transition from brittle faulting to cataclastic flow: Permeability evolution, J. Geophys. Res. 102, 30273041 .

Zubtsov S., Renard F., Gratier J.-P., Guiguet R., Dysthe D.K., Traskine V.Y. (2004) Experimental pressure solution creep of polymineralic aggregates, Tectonophysics $\mathbf{3 8 5}, 45-57$.

Yielding G., Freeman B., Needham D.T. (1997) Quantitative Fault Seal Prediction, AAPG Bull. 81, 897-917.

Final manuscript received in May 2010 Published online in February 2011

\section{Copyright (C) 2011 IFP Energies nouvelles}

Permission to make digital or hard copies of part or all of this work for personal or classroom use is granted without fee provided that copies are not made or distributed for profit or commercial advantage and that copies bear this notice and the full citation on the first page. Copyrights for components of this work owned by others than IFP Energies nouvelles must be honored. Abstracting with credit is permitted. To copy otherwise, to republish, to post on servers, or to redistribute to lists, requires prior specific permission and/or a fee: Request permission from Information Mission, IFP Energies nouvelles, fax.+33147527096, or revueogst@ifpen.fr. 